\title{
DIFFERENT METHODOLOGIES AND USES OF THE HURST EXPONENT IN ECONOPHYSICS
}

\author{
MARÍA DE LAS NIEVES LÓPEZ GARCÍA \\ Departamento de Economía y Empresa. UNIVERSIDAD DE ALMERÍA, ESPAÑA \\ E-mail: marian00lg@hotmail.es \\ JOSE PEDRO RAMOS REQUENA \\ Departamento de Economía y Empresa. UNIVERSIDAD DE ALMERÍA, ESPAÑA \\ E-mail: jpramosre@ual.es
}

\begin{abstract}
The field of econophysics is still very young and is in constant evolution. One of the great innovations in finance coming from econophysics is the fractal market hypothesis, which contradicts the traditional efficient market hypothesis. From fractal market hypothesis new studies/models have emerged. The aim of this work is to review the bibliography on some of these new models, specifically those based on the Hurst exponent, explaining how they work, outline different forms of calculation and, finally, highlighting some of the empirical applications they have within the study of the financial market.
\end{abstract}

Keywords: econophysics, fractal market, models and Hurst exponent

Diferentes metodologías y usos del exponente de Hurst en econofísica

\section{RESUMEN}

El campo de la econofísica es todavía muy joven y está en constante evolución. Una de las grandes innovaciones en las finanzas provenientes de la econofísica es la hipótesis del mercado fractal, que contradice la hipótesis tradicional del mercado eficiente. De la hipótesis del mercado fractal han surgido nuevos estudios/modelos. El objetivo de este trabajo es revisar la bibliografía sobre algunos de estos nuevos modelos, en concreto los basados en el exponente Hurst, explicar cómo funcionan, esbozar diferentes formas de cálculo y, finalmente, destacar algunas de las aplicaciones empíricas que tienen dentro del estudio del mercado financiero.

Palabras clave: econofísica, mercado fractal, modelos y exponente de Hurst

Clasificación JEL: G1

Artículo recibido el 11 de mayo de 2019 y aceptado el 25 de mayo de 2019 Artículo disponible en versión electrónica en la página www.revista-eea.net ISSN 1697-5731 (online) - ISSN 1133-3197 (print) 


\section{INTRODUCTION}

Econophysics is a fairly recent field of research that applies theories and methods of statistical physics to try to understand and solve economic problems, especially those with stochastic aspects and non-linear dynamics.

This new field of study arose out of physicists' interest in explaining the social sciences in a mathematical way. It is believed that this new field of research began to take form in the 1990s at the Santa Fe Institute in New Mexico, which specialized in the study of complex systems. Although the use of the term econophysics is more recent because it was created by the scientist Eugene Standley from Boston University (H.E. Stanley, 1999).

Economics has traditionally been a theoretical science, taught qualitatively rather than mathematically. It was not until the middle of the 20th century that mathematical formalization began to gain importance. A sample of this is one of the fundamental works in the economy of Paul A. Samuelson "Fundamentals of economic analysis", whose economic thought develops a totally theoretical science far from the contact with the observation of reality.

The econophysics tries to solve this distancing of the economy with the observable facts by creating links with the theoretical models. Within the wide range of problems that the economy studies, it is possibly in finance where the econphysicists have more presence, being the study of the dynamics of market prices one of the most outstanding subjects. The main reason why econophysics has been able to gain such strength in a short time in this kind of studies is due to the availability of large amounts of financial data collected from the 1980 s to the present, which make it possible to apply various mathematical models from physics, such as the study of memory in the financial market.

To make a complete classification of the different branches of econophysics is very complicated since it is a fairly recent science and subject to many changes. Even so, after a bibliographic search, we have decided to present a brief classification of some of the most interesting subareas currently within the field of econophysics (O. Matos, 2006).

The first of the areas we highlight focuses on the analysis of the time series of yields. Traditionally, economists perform these analyses under the efficient market hypothesis and its modeling through the standard Brownian model. Efficiency is achieved on the basis of information, since the theory states that the prices of the different assets that make up the market incorporate all relevant information completely and instantaneously, so that asset prices will be fair and equitable if the market is efficient from the perspective of information.

The great disadvantage of this scenario for the investor is that it makes it very difficult to achieve extraordinary returns with knowledge of prices and past returns only. Faced with this approach, economists conclude that return movements are independent over time and that there is therefore no memory in the financial market.

However, empirical studies have emerged that reject this theory on the basis of market observations, so that the rationality and absence of memory in asset prices is beginning to be questioned. Because of these assumptions it began to be demonstrated that prices reflect a fractional Brownian movement, which allows the demonstration of the existence of memory in the market (Lindgren, 2007; M. Mitchell, 2001).

The second area focuses on the study of distributions. Traditionally, in economics, work has been carried out under the Gaussian distribution approach to explain the movements in the prices of financial assets. This thought persisted for quite some time, but researchers emerged who posed several problems to the Gaussian model and with them came possible solutions. One of the most important authors in this area is the French mathematician Benoit Mandelbrot, who observed that the series of logarithmic differences in daily cotton prices was more pointed than a normal distribution, so its extreme values appear more often than in a Gaussian, as the distribution queues are heavier. From these observations it was verified that the standard Brownian model and the normal distribution no longer fit with the observed reality, and as an alternative, Mandelbrot proposed several works, where he focused on the study of the long-term memory of the market based on a stable Pareto distribution (Fama, 1963). 
The third area is network theory. According to standard finance theory, the diversification of risk through different financial institutions and instruments makes each company, and by extension the market, more secure and stable. However, network theory helps us in the study of markets, and makes us see that an over-connected network makes it very easy for financial crises to spread worldwide. The most obvious example is the recent financial crisis of 2007, which harmed, to a greater or lesser extent all banks in the world for possessing some toxic asset of subprime mortgages. Of course, the countries that had the least problems in the last crisis were the least developed, since the scarce globalization of their finances protected them from the contagion of the crisis (Newman, 2003).

We highlight one last area of study based on the agent system. This type of models tries to simulate the actions of autonomous individuals within an environment to determine what effects they produce in the whole system. This theory from the perspective of a financial market simulates a large number of independent agents, which have various alternatives in making their decisions within the market. The joint activity of all individuals makes up the market price, which is always known by each individual, and they use the price history to make their decisions (Ausloos, 2006).

As we can see, with this brief review of some of the different subareas that make up econophysics, we are faced with a science with a very large field of research that is still being formed. In this paper we focus more on the study of the long-term memory of the market through Hurst's exponent method.

The study of memory processes has become widespread in recent years in a multitude of knowledge disciplines, from hydrogeology to meteorology, including the study of Internet traffic patterns and even heartbeat patterns (Hurst, 1951; Mandelbrot \& Wallis, 1968; Movahed \& Hermanis, 2008; Peng et al., 1992).

As far as social sciences are concerned, more specifically as far as economics is concerned, the study of memory processes captured the interest of researchers during the 1970s (Mandelbrot, 1971, 1972). Mandelbrot in 1997 was the pioneer in introducing Hurst's exponent in the study of financial time series (Mandelbrot, 1997).

In recent decades the study of memory processes has extended from macroeconomics (Conniffe \& Spencer, 2000; Diebold \& Rudebusch, 1989; Hassler, 1994; Hassler \& Wolters, 1995), to finance, the latter being the field in particular where it is having the greatest acceptance. The interest of market finance within the study of memory processes is based on the fact that they are considered as a valid alternative to test, in a relatively simple way, the Efficient Market Hypothesis. Although this is a very simplistic approach, what we are going to do next, in general terms, if a certain title presents long-term memory, it could be said that it presents a cyclical behavior and therefore does not follow a random process, which would directly confront the efficiency hypothesis. However, as Sanchez-Granero, Trinidad-Segovia, García, \& Fernández-Martínez (2015) indicate, this approach is by no means as straightforward as some authors would have us believe, since there are other aspects that need to be considered when reaching conclusions. To conclude, the works of (Mandelbrot, 1997; Sanchez-Granero, Fernández-Martínez, \& Trinidad-Segovia, 2015; Sanchez-Granero, Trinidad-Segovia, et al., 2015; Sánchez-Granero, Trinidad-Segovia, \& Garcia Perez, 2008; Trinidad-Segovia, Fernández-Martínez, \& Sanchez-Granero, 2012), among others, are of interest in the field of finance. Numbering all of them is highly tedious while not very rigorous given the amount of work that appears annually on this subject.

Having made this brief introduction to econophysics and the process of memory, we will focus on the main objective of our work, the exponent of Hurst. One of the characteristics of this exponent in the study of financial markets is that it bases its approach on the fractal market hypothesis, so we dedicate section 2 to its study. In section 3 we develop the definition of the Hurst exponent and some of its main forms of calculation. In section 4 we present the reviews of some of the articles published with the exponent so that the reader can understand the versatility of its use within the study of the financial market. Finally, we present a brief summary and provide some conclusions about the study carried out. 


\section{EFFICIENT MARKET HYPOTHESIS VS. FRACTAL MARKET HYPOTHESIS}

\subsection{Efficient market}

A market is efficient if its asset prices reflect all available information and adjust fully and immediately to new information. If the market is efficient, changes in security prices are unpredictable and therefore behave like a random walk.

The starting hypotheses for an efficient market are:

- Markets have no memory.

- All market participants have the same information available.

- Financial assets are in competition with each other, so that all information affecting securities is immediately reflected in their prices.

- All assets are perfectly valued.

- There are different levels of efficiency depending on the information available in the market.

- Weak efficiency. Each title reflects historical price information.

- Efficiency semifuerte. The prices reflect all the historical information and all the public information of the companies and their environment.

- Strong efficiency. Prices reflect all past information, public or private.

Based on the efficient market hypothesis, several models were developed to study the market, such as the traditional models of Markowitz, Sharpe and CAPM.

These models have been widely criticized for presenting a very simplified view of reality and for basing much of their previous hypotheses on assumptions without empirical foundations. For this reason, these models are not capable of explaining the movements of financial markets over long periods of time.

\subsection{Definition and properties of fractals}

The term fractal comes from the Latin "fractus" which means "fragments. A fractal is a structure composed of small parts similar to the original figure and repeated on different scales.

There are three properties that define fractals:

- Self-similarity. Scaling consists of generating a similar copy of an object on a different scale. To achieve this, a scaling factor is used, so two objects are similar if they have the same geometry, but different size.

- Self-affinity. It occurs when a fractal object remains invariant under different scales in all directions. The mathematical processes of creating fractal structures are iterations of simple rules of the initial objects, so small changes can cause a huge change in patterns at the macro and micro levels.

- Fractal dimension. It allows to quantify how rugose is a curve from a simple classification:

$\circ \quad$ The points have dimension 0 .

- The lines have dimension 1.

- Surfaces have dimension 2.

- Volumes have dimension 3.

- Quantifying fractals allows us to define the proportion of physical space that is occupied by fractal objects.

\subsubsection{Fractal analysis.}

Fractal analysis serves to determine the three properties of fractals (fractal dimension, self-similarity and self-affinity) in fractal objects. There are several techniques to find the fractal dimension. Those based on "fractal analysis" show that the market has volatile fluctuations that tend to repeat with a certain trend (temporal correlation) and that its probability distribution has wide tails, so that extreme events may occur more frequently than the one defended by the normal distribution. The fractal concept is used to identify the existence of order in many non-linear problems. 
At first, the use of fractals had no useful application beyond mathematical curiosities, but over time various applications have been found in different fields such as biology, medicine or finances.

\subsubsection{Fractals in Finance}

The technical analysis in finance is based on the study of market movements reflected through charts. These charts comply with the three properties of fractals:

- They are auto-similar, since in the graphs that reflect the fluctuations of the prices, if we do not specify the scale in which they are measured it is not possible to know if they are daily, monthly or annual.

- The graphs have a high sensitivity to initial conditions, as from similar conditions can show a completely different behavior.

- Its fractal dimension is not integer, it is between 1 and 2.

The characteristics proposed for the fractal market, and with which they seem to coincide with the reality of prices, contradict the assumptions of normality and independence that the efficient market hypothesis defends.

These contradictions have given rise to the interest in studying the correlations between successive prices, as is the case with Hurst, and which is related to the fractal dimension.

\subsection{Fractal market}

The fractal market assumption focuses on the impact of investors' liquidity and time horizons. The objective of this hypothesis is to provide a model of investor behaviour and market price movements.

The model's previous assumptions are:

- Market stability depends on its participants having different time horizons, thus ensuring liquidity in the market.

- Continuous information related to market sentiment and technical factors are more important in the short term. As the term is extended, fundamental information takes on importance.

- If something happens that questions the validity of fundamental information, long-term investors either cease to participate in the market or shorten its time horizon.

- Prices reflect both technical (short term) and fundamental (long term) information.

- If a security has no link to economic cycles, it will not have a long-term investment horizon, with liquidity and technical information dominating.

\section{THE EXPONENT OF HURST}

The origin of the Hurst exponent goes back to 1951 when the hydrologist Harold Edwin Hurst, (1951) proposes a method to optimize the storage capacity of a reservoir intended to regulate the natural contributions of the Nile river, bearing in mind the cyclical trends of the flow, times of drought and by extension of floods. His methodology is based on the idea that many natural phenomena exhibit a behavior that can be characterized by a random biased process, in which there is memory among the observations, that is, that the events of one period influence all of the following.

In fractal geometry, the Hurst exponent has been defined by $\mathrm{H}$ or by Hq. It quantifies the relative tendency of a time series to return strongly to the mean or group in one direction (Kleinow, 2002). Depending on the obtained result we can know if a temporal series is persistent or not persistent. If persistence is found, it is a sign of the non-existence of white noise, so it could be said that there is some type of dependence between the data, that is, we would be checking if the data behave according to the ordinary Brownian movement or, on the contrary, there is memory within the series of data.

There are three possible interpretations of the results according to the value obtained in the Hurst exponent:

A value $\mathrm{H}=0.5$ is associated with an uncorrelated series, so it implies an independent process. In fact, it is the value applicable to series for which autocorrelations in small time delays may initiate a completely uncorrelated series, but where the absolute values of autocorrelations decrease exponentially and rapidly to zero. This contrasts with the typical decay of the power law for cases $0,5<\mathrm{H}<1$ and $0<\mathrm{H}<0,5$. 
- An $\mathrm{H}$ value in the range 0.5 - 1 indicates a time series with positive long-term autocorrelation, which implies persistent time series, that is, they show long-term memory. For example, in a series of persistent data with high (low) values, other high (low) values are likely to follow and remain so for a considerable period of time.

- A value in the range $0-0.5$ indicates a time series with long term switching between high and low values in adjacent pairs, which implies antipersistence in the time series. All this means that possibly a single high value will be followed by a low value and that the value will then tend to be high, with a tendency to change between high and low values over the long term.

Among the different methodologies developed to obtain a numerical value of this exponent, the most popular is the R/S analysis, developed by Mandelbrot in 1969. However, and practically since its birth authors such as Lo (1989) and more recently others such as Weron (2002) or (Sánchez-Granero et al., 2008), have shown that the resulting value for the exponent when the length of the time series is too short is far from adequate, accentuating the problem in the case of financial series. For this reason, one of the classic lines of research consists of refining and improving the estimation techniques of the Hurst exponent, either by improving the R/S analysis (Lo, 1989; Weron, 2002) or through the development of new methodologies, among which we can mention the Semiparametric Hudaks Method (GPH) (Geweke \& Porther Judak, 1983), the analysis Quasi Maximo Verosimilitude (QML) (Haslett \& Raftery, 1989), the exponent of Generalized Hurst (GHE) (Barabasi \& Vicsek, 1991), the Periodogram method (Taqqu, Teverovsky, \& Willinger, 1995), the waveltets methodology (Veitch \& Abry, 1999), the centred moving average (CMA) method (Alessio, Carbone, Castelli, \& Frappietro, 2002), the MF-DFA methodologies (Kantelhardt et al., 2002), the Lyadpunov exponent (Bensaïda, 2014; Das \& Das, 2006), methods based on geometric procedures (GM) (Sanchez-Granero, Fernández-Martínez, et al., 2015), and more recently the fractal dimension algorithm (FD) (Fernández-Martínez, Sanchez-Granero, \& Trinidad-Segovia, 2013).

\subsection{Models}

In this section, we will explain the main methods that have been developed for the calculation of the Hurst Exponent.

The classical method for the study of memory processes is the one known as Hurst exponent (Hurst (1951)), and among different methodologies developed to obtain a value of this exponent, the most popular is the R/S analysis, developed by Mandelbrot in 1969. However, and practically since its birth, authors such as Lo (1989), and more recently others such as Weron (2002) or Sánchez et al (2008), have shown that the resulting value for the exponent when the length of the time series is too short is far from adequate, accentuating the problem in the case of financial series

\subsubsection{R/S Analysis}

The R/S method is the best-known procedure for estimating the Hurst exponent of a time series, which was proposed by Mandelbrot and Wallis in 1969, on the basis of Hurst's earlier work.

For a time series of returns of length $\mathrm{n}$, and for each $m=2^{k}<n$ we divide the series into $d=\frac{n}{m}$ non-overlapping blocks of length $\mathrm{m}$. Then:

1. We calculate the mean $E_{i}$ and the standard deviation $S_{i}$ of each block $B=\left\{B_{1}, \ldots, B_{m}\right\}$ for all $i=$ $1, \ldots, d$.

2. We normalize the data of each $B_{i}$ block, subtracting its mean $E_{i}$ mean, that is, $N_{j}=B_{j}-E_{i}$, for $j=1, \ldots, m$.

3. We calculate the cumulative time series (with mean 0) for each block: $C_{j}=\sum_{k=1}^{j} N_{k}$, for $j=$ $1, \ldots, d$.

4. We calculate the range of $C_{j}$ for each block: $R_{i}=\operatorname{má} x\left\{C_{j}: j=1, \ldots, m\right\}-\operatorname{mí}\left\{\left\{C_{j}: j=1, \ldots, m\right\}\right.$, for $i=1, \ldots, d$.

5. We change the range: $R_{i} / S_{i}$, for $i=1, \ldots, d$. 
6. Finally, we calculate the average of the range change: $R S_{m}=\frac{1}{d} \sum_{i=1}^{d} \frac{R_{i}}{S_{i}}$

The HR/S value is the slope of the linear regression of the logarithm RS_m against the logarithm $\mathrm{m}$.

\subsubsection{The Trend Fluctuation analysis approach (DFA)}

DFA is another classical algorithm for estimating the self-similarity exponent of a random process that was introduced by Peng in 1994. This method allows us to check the correlation and scale properties of a time series (Di Matteo et al (2005), Ausloos (2000), Liu et al (1997)). The formulation for such a procedure can be done in the following way.

Dada una serie temporal de retornos de longitud n y para cada $m=2^{k}<n$, dividimos la serie en $d=\frac{n}{m}$ bloques no solapados de longitud m. Entonces:

1. Determine the local trend of each block.

2. Be $y_{j}$, with $j=1, \ldots m$, the process without trend in each block, that is, the difference between the original value of the series in the block and the local trend.

3. For each block we calculate $B_{i}=\sum_{j=1}^{m} y_{j}^{2}$ for $i=1, \ldots, d$.

4. We calculate the statistic $F_{m}^{2}=\frac{1}{d} \sum_{i=1}^{d} B_{i}$, which is the mean variance of the process without trend.

The value of $H_{D F A}$ is the slope of the linear regression that compares the $\log \left(F_{m}\right)$ and the $\log (m)$.

It is noted that both $H_{R / S}$ and $H_{D F A}$ estimators provide information on memory, but not on the distribution of process increments. In addition, it is observed that both estimators are based on the variance or standard deviation of the process or its increments, but even if the variance (or standard deviation) becomes infinite, both estimators continue to work appropriately (Montanari et al (1999)).

\subsubsection{The Generalized Hurst Exponent (GHE)}

Introduced by Barabasi et al in 1991, GHE is one of the most popular methods for calculating the Hurst exponent. It is a generalization of the classical approach provided by Hurst (1951) and relates to the scale behaviour of some statistical properties of a time series. It is considered a powerful tool for detecting multifractuality by scaling the q-order moments of the distribution of increments. This scaling property is determined by an $H_{G H E}$ exponent that is normally connected to the long-term statistical dependence of the time series.

In particular, it has been verified that these statistical properties of the time series scale both with the observation period (T) and with the resolution of the time window. For this, the following statistic is considered:

$$
K_{q}(\tau)=\frac{<|X(t+\tau)-X(t)|^{q}>}{<|X(t)|^{q}>}
$$

where $(\tau)$ can vary between 1 and $\tau_{\max }$. So $\tau_{-} \max$ is generally chosen as a quarter of the length of the series and $<.>$ describes the average of the sample during the time window.

Therefore, the GHE is defined from the behaviour on the scale of the statistician $K_{q}(\tau)$,, given by the Law of Powers:

$$
K_{q}(\tau) \propto \tau^{q H(q)}
$$

The GHE is calculated as an average of a list of values of the expression contained in equation 2, for different values from $\tau$ (Aste, Di Matteo et al (2005), Barunik et al (2010)).

\subsubsection{Fractal Dimension Algorithms (FD)}

Developed by Sánchez et al (2012), its foundation is based on the concept of fractal dimension of a curve, previously defined by Fernández et al (2012). The authors consider the fractal dimension as a generalization of the Hurst exponent, whose main advantage is that it can be calculated for a wider range of movements, not necessarily Brownians. 
The authors define four versions of the FD algorithm, the first three appearing in Sánchez et al (2012) and the last version in Fernández et al (2014), where the previous FD and GM algorithms are also refocused. In this way, the authors indicate that the FD algorithms are calculated in the following way:

$X$ denotes a random variable whose absolute value of the moment of order qth is defined as $m_{q}(X)=$ $E\left[X^{q}\right]$ and for each $\mathrm{q}>0$ an expected value can be obtained.

So, let $\mathrm{X}$ be a random process with stationary increments and let's suppose that there is a parameter $\mathrm{H}>0$ such that $M(T, \omega) \sim T^{H} M(1, \omega)$ is fulfilled.

So if we take q-powers in the above equation, then we have to:

$$
M(T, \omega)^{q} \sim T^{q H} M(1, \omega)^{q}
$$

for all $\mathrm{q}>0$. We will consider $T_{n}=1 / 2^{n}$ as a reasonable discretion of the time period $\mathrm{T}$ for all $\mathrm{n} \in \mathbb{N}$. In this way:

$$
M\left(T_{n}, \omega\right)^{q} \sim T_{n}^{q H} M(1, \omega)^{q}
$$

for all $\mathrm{q}>0$ and all $\mathrm{n} \in \mathbb{N}$, according to equation 4 . Thus, if we denote by $X \_n$ the cumulative range of the period $T_{n}$-period of the random process $X$, we get $X_{n}=M\left(T_{n}, \omega\right)=M\left(1 / 2^{n}, \omega\right)$, parat all $\mathrm{n} \epsilon$ $\mathbb{N}$, therefore we have $X_{n}^{q} \sim T_{n}^{q H} X_{0}^{q}$ for all $\mathrm{n} \in \mathbb{N}$ and all $\mathrm{q}>0$. In this way, we have the following relationship between the q-potencies of the consecutive periods of the cumulative ranges of : $X_{n}^{q} \sim 2^{q H} X_{n+1}^{q}$.

In addition, since the two preceding random variables have the same function of joint and finite distribution, then their means, called $E\left[X_{n}^{q}\right]=2^{q H} E\left[X_{n+1}^{q}\right]$, must be equal, which leads to the following expression:

$$
m_{q}\left(X_{n}\right)=2^{q H} m_{q}\left(X_{n+1}\right)
$$

relates the moments of order q consecutive for all $n \in \mathbb{N}$ and all $q>0$. Equation 5 is equivalent to the following:

$$
m_{q}\left(X_{n}\right)=\frac{1}{2^{n q H}} m_{q}\left(X_{0}\right)
$$

Therefore, it is sufficient to take base 2 logarithms on both sides of equation 5 , to obtain the following expression:

$$
\log _{2}\left(\frac{m_{q}\left(X_{n}\right)}{m_{q}\left(X_{n+1}\right)}\right)=q H
$$

Where the linear relationship between $\log _{2}\left(\frac{m_{q}\left(X_{n}\right)}{m_{q}\left(X_{n+1}\right)}\right)$ and q is established, given that $m_{q}\left(X_{n}\right)$ exists for $\mathrm{n} \in \mathbb{N}$. The self-similarity index $\mathrm{H}$ of the random process $\mathrm{X}$ can be clearly estimated by equation 7 as $H=\frac{1}{q} \log _{2}\left(\frac{m_{q}\left(X_{n}\right)}{m_{q}\left(X_{x+1}\right)}\right)$. Thus, this generic approximation (for $\mathrm{q}>0$ ) is denoted as FD for the calculation of the self-similarity exponent of a random $X$ process.

In the same paper Sánchez et al (2012), they demonstrate the relationship between FD and GM algorithms.

\section{HURST EXPONENT APPLICATIONS}

In this section we want to reflect some of the real applications that has the exponent of Hurst in the field of finance. Although it is impossible to reflect all the work done so far, we have made a small compendium with the aim of highlighting the usefulness of the exponent in the market study and time series. 
Let's start by talking about some of the studies focused on market efficiency.

In Mitra, (2012) they calculated the Hurst exponent (using the R/S method) for twelve stock index series using the daily values of the last ten years. They found that the exponent value for the entire series is around 0.50 which confirms the efficiency of the market. But this value varies widely when the series is divided into smaller series of 60 trading days. Finally, they do a small study to study the relationship between the value of the Hurst exponent and the profitable trading opportunity, using the 60-day time series. The results showed that in periods where the exponent obtains high values they have the potential to produce better trading profits.

There are many more studies that measure the efficiency of markets around the world, but instead of continuing to review this type of studies, we have seen fit to focus on some work that focus their study of market efficiency in order to classify markets into emerging and mature, and highlight with their results the differences between them.

In Cajueiro \& Tabak, (2004) they focused on confirming the claim found in the financial literature that emerging markets are becoming more efficient over time. To verify this claim they proposed the calculation of the Hurst exponent (through the R/S method) using a time horizon of 4 years. The data they used to study emerging countries came from Latin America and Asia. After conducting their study they found that most emerging markets confirm the initial assertion, as the data showed that most of the markets studied are becoming more efficient over time.

In addition, to check whether the results depend on short-term memory and volatility of yields, they tested using the AR-GARCH procedure and presented the Hurst exponent values at three levels. They concluded that Hurst exponents vary over time due to changes in the dynamics of the underlying return time series. But this is not explained by either short-term dependencies or variable volatility over time, as Hurst exponents are variable over time even after adjusting for short-term dependency and variable volatility over time. Empirical results for emerging markets suggest that on average there appears to be a downward trend in the Hurst exponent for the period 1992-2002. Finally, they concluded that developed countries appear to be more efficient than emerging countries.

In J. A. O. Matos, Gama, Ruskin, Sharkasi, \& Crane, (2008) they applied a method they called TSH, which is a combination of the DFA method along with time and scale dependence (Time and Scale Hurst exponent). The objective was to study the evolution of the market over time for a series of markets, and thus classify them into three groups:

- Mature: they obtain $\mathrm{H}$ values around 0.5. The presence of regions with higher $\mathrm{H}$ values is limited to small periods and is well defined both in time and scale.

- Emerging: they obtain $\mathrm{H}$ values much higher than 0.5. The presence of regions with $\mathrm{H}$ values around 0.5 is well defined both in time and scale.

- Hybrids: the distinction between the mature and emergent phases is not well determined, as behaviour seems to mix at all scales.

This classification allowed them to distinguish major events affecting several markets, as opposed to local fluctuations in a single (or few) markets. The examples given by the authors are the Asian tiger crashes (1997), 11 September 2001 and the Madrid bomb (2004).

Another focus in the analysis of the efficiency of financial markets is the study of periods of financial crisis. Here are some examples.

In Anagnostidis, Varsakelis, \& Emmanouilides (2016), empirical research was conducted on the impact of the 2008 financial crisis on the efficiency of 12 stock markets in the euro area. The method for testing efficiency was the GHE. In general, they conclude that in periods of financial instability the gregarious behaviour of market agents can lead to abnormal price movements and, in turn, to significant amounts of inefficiency in the market.

Continuing with the study of the financial crisis of 2008, but this time from a more international perspective, we can mention the work of Lahmiri, (2015). The purpose of this study was to investigate the long-term dependence on the trend and variation of price series and market yields with values before, during and after the 2008 financial crisis. They used variable mode decomposition (VMD), a newly introduced technique for signal processing is adopted to decompose stock market data into a finite set of modes in order to obtain long-term trends and short-term movements of stock market data. DFA and 
$\mathrm{R} / \mathrm{S}$ analyses are then used to estimate the Hurst exponent in each variation mode obtained from VMD. The results of the study showed that, for both the price series and the yield series of the twelve international stock markets in the sample, they show that long-term trends are persistent while shortterm variations are antipersistent before, during and after the 2008 financial crisis.

Although the most recent financial crisis is that of 2008, we have also found some interesting work on previous crises that have left their mark on financial history, such as Alvarez-Ramirez, Alvarez, Rodriguez, \& Fernandez-Anaya, (2008) focused on studying the behavior of U.S. stock markets. He calculated the temporal variations of the Hurst exponent using the DFA method on the daily historical indices of the Dow Jones (1928-2007) and S\&P-500 (1950-2007). The exponent shows erratic dynamics with some episodes altering persistent low and high behavior. The results based on data suggest that the end of the Bretton Wood system and the great fall of the market in 1987 introduced new rules and actors that endowed the dynamics of the stock market with a more efficient operation.

In 2017, Ramos-Requena et al introduce Hurst's exponent in the statistical arbitrage strategy called Pairs Trading. This strategy was created in the 1980s by an American investment group. Pairs Trading consists of looking for two shares whose prices have shown similar patterns in the past and arbitrate them when their prices diverge (Pizzutilo, 2013). Since its appearance there have been many studies, and they have included different methods for the selection of pairs, some very simple as the method of distance and correlation and others more complex as the approaches of cointegration and copulation.

Ramos-Requena et al (Ramos 2017) use the GHE (Generalized Hurst Exponent) to carry out their study, using the Dow Jones data for the period 2000-2015, and make a comparison with the classical methods (distance and correlation). Reaching the conclusion that this model works better by increasing the number of pairs that make up the portfolio and in periods of high volatility, it obtains returns that are much higher than the classic methods.

Finally, we will highlight the introduction of Hurst's exponent in the statistical arbitrage strategy called Pairs Trading. This strategy was created in the 1980 s by a American investment group. Pairs Trading consists of looking for two shares whose prices have shown similar patterns in the past and arbitrate them when their prices diverge (Pizzutilo, 2013). Since its appearance there have been many studies carried out, and they have included different methods for the selection of pairs, some very simple as the method of distance and correlation and others more complex as the approaches of cointegration and copulation.

In Ramos-Requena (2017) they use the GHE (Generalized Hurst Exponent) to carry out their study, using the Dow Jones data during the period 2000-2015, and make a comparison with the classical methods (distance and correlation). Reaching the conclusion that this model works better by increasing the number of pairs that make up the portfolio and in periods of high volatility, it obtains returns that are much higher than the classic methods.

\section{SUMMARY AND CONCLUSIONS}

The field of econophysics is still very recent and is in constant evolution. One of the most important innovations in finance from this field has been the fractal market hypothesis, which goes against the traditional efficient market hypothesis.

Financial markets are far from having the behavior that defends the efficient market hypothesis, making their predictions do not conform to reality, so traditional analytical tools should be changed to improve the results of predictive models. From the perspective of the fractal market hypothesis, prices have a fractal behavior so the use of fractal geometry is more appropriate to analyze the market more realistically.

In fractal models, unexpected patterns may appear, so these models are a good option for those who operate within the stock exchange, since they can analyze the value of a variable over time, thus being able to glimpse a certain order within the apparent chaos in the history of financial data.

One of the new models that has emerged from the fractal market hypothesis are those based on Hurst's exponent, which has been the focus of our study. 
The form of calculation of this exponent is not unique and we have only dealt with some of the most recurrent forms in literature. Nowadays, new forms of calculation of the Hurst exponent continue to emerge, with the aim of making it better adapted to the economic context in which we work. An example of these innovations can be found in the latest model we have proposed, the FD4.

Just as there are several ways of calculating the Hurst exponent, there are also several fields of study in which it can be used. In this article we have focused on showing the most practical applications for the study of the market, through the analysis of the efficiency, with which we have seen that it is possible to obtain a classification of markets (emerging/mature) or even the interpretation of the market in periods of crisis.

Despite all the studies published so far, it will take some time before a complete theory of the dynamics of financial markets can be obtained. In the meantime, we have to continue working on the search for more precise models, as it is believed that with the correct use of the Hurst exponent we could know the trend that follows a given value and controlling this coefficient could give us the signal of when the changes in trend occur or their continuation.

We believe that this field of study will be further developed and new tools will be created to accurately predict price changes and thus explain some of the market behaviours and even to propose trading models with which to achieve significant returns.

\section{BIBLIOGRAFHICAL REFERENCES}

ALESSIO, E., CARBONE, A., CASTELLI, G., \& FRAPPIETRO, V. (2002). Second-order moving average and scaling of stochastic time series. The European Physical Journal B-Condensed Matter and Complex Systems, 27, 197-200.

ALVAREZ-RAMIREZ, J., ALVAREZ, J., RODRIGUEZ, E., \& FERNANDEZ-ANAYA, G. (2008). Time-varying Hurst exponent for US stock markets. Physica A: Statistical Mechanics and Its Applications, 387(24), 6159-6169. https://doi.org/10.1016/j.physa.2008.06.056

ANAGNOSTIDIS, P., VARSAKELIS, C., \& EMMANOUILIDES, C. J. (2016). Has the 2008 financial crisis affected stock market efficiency? the case of Eurozone. Physica A: Statistical Mechanics and Its Applications, 447, 116-128. https://doi.org/10.1016/j.physa.2015.12.017 Aste, T. Generalized exponent of a stochastic variable. http://www.mathworks.com/matlabcentral/fileexchange/30076.

AUSLOOS, M. (2006). Econophysics of Stock and Foreing Currency Exchange Markets. Econophysics and Sociophysics, 249-278.

BARABASI, A. L., \& VICSEK, T. (1991). Multifactality of self-affine fractals. Physical Review A, 44, 2730.

BARUNIK, J., \& KRISTOUFEK, L. (2010). On Hurst exponent estimation under heavy-tailed distributions. Physica A: Statistical Mechanics and its Applications, 389(18), 3844-3855.

BENSAIIDA, A. (2014). Noisy chaos in intraday finacial data: Evidence from the American index. Applied Mathematics and Computation, 226, 258-265.

CAJUEIRO, D. O., \& TABAK, B. M. (2004). The Hurst exponent over time: Testing the assertion that emerging markets are becoming more efficient. Physica A: Statistical Mechanics and Its Applications, 336(3-4), 521537. https://doi.org/10.1016/j.physa.2003.12.031

CONNIFFE, D., \& SPENCER, J. E. (2000). Apporximating the Distribution of the R/S statistic. Economic and Social Review, 31, 237-248.

DAS, A., \& DAS, P. (2006). Does composite index of NYSE represents chaos in the long time scale? Applied Mathematics and Computation, 174, 483-489.

DIEBOLD, F. X., \& RUDEBUSCH, G. D. (1989). Long memory and persistence in aggregate output. Journal of Monetary Economics, 24, 189-209.

DI MATTEO, T., ASTE, T., \& DACOROGNA, M. M. (2005). Long-term memories of developed and emerging markets: Using the scaling analysis to characterize their stage of development. Journal of Banking \& Finance, 29(4), 827-851.

FAMA. (1963). Mandelbrot and stable Paretian hypothesis. 1The Journal of Bussines, 36(4), 420-429.

FERNÁNDEZ-MARTÍNEZ, M., \& SÁNCHEZ-GRANERO, M. A. (2012). Fractal dimension for fractal structures: A Hausdorff approach. Topology and its Applications, 159(7), 1825-1837.

FERNÁNDEZ-MARTÍNEZ, M., SANCHEZ-GRANERO, M. A., \& TRINIDAD-SEGOVIA, J. E. (2013). Measuring the self-similarity exponent in Lévy stable processes of financial time series. Physica A: Statistical Mechanics and Its Applications, 392, 5330-5345.

FERNÁNDEZ-MARTíNEZ, M., SÁNCHEZ-GRANERO, M. A., SEGOVIA, J. T., \& ROMÁN-SÁNCHEZ, I. M. (2014). An accurate algorithm to calculate the Hurst exponent of self-similar processes. Physics Letters A, 378(3233), 2355-2362.

GEWEKE, J., \& PORTHER JUDAK, S. (1983). The estiamtion and application of long memori time serie models. Journal of Time Series Analysis, 4, 221-238.

H.E. STANLEY. (1999). Econophysics: can physicists contribute to the science of economics? Computing in Science \& Engineering, 1 (1), 74-77. 
HASLETT, J., \& RAFTERY, A. E. (1989). Space-time modelling with long-memory dependence: Asses-sing Irleands wind power resource. Applied Statistis, 1-50.

HASSLER, U. (1994). specification of long memory in seasonal time series. Journal of Time Series Analysis, 15, 19-30.

HASSLER, U., \& WOLTERS, J. (1995). Long memory in infation rates: Interantioal evidence. Journal of Business \& Economic Statistics, 13, 37-45.

HURST, H. E. (1951). Long-term storage capacity of reservoirs. Trans. Amer. Soc. Civil Eng., 116, 770-808.

KANTELHARDT, J. W., ZSCHIEGNER, S. A., KOSCIELNY BUDE, E., HAVLIN, S., BUNDE, A., \& STANLEY, H. E. (2002). Multifractal detrended flutuation analysis of nonstationary time series. Physica A: Statistical Mechanics and Its Applications, 316, 87-114.

KLEINOW, T. (2002). Testing continous time models in financial markets. Humboldt-Universitat.

LAHMIRI, S. (2015). Long memory in international financial markets trends and short movements during 2008 financial crisis based on variational mode decomposition and detrended fluctuation analysis. Physica A: Statistical Mechanics and Its Applications, 437, 130-138. https://doi.org/10.1016/j.physa.2015.05.067

LINDGREN, H. (2007). Long-Short Story Short. New York Magazine.

LIU, Y., CIZEAU, P., MEYER, M., PENG, C. K., \& STANLEY, H. E. (1997). Correlations in economic time series. Physica A: Statistical Mechanics and its Applications, 245(3-4), 437-440.

LO, A. W. (1989). Long-term memory in stock market prices. Econometrica, 59, 1279-1313.

M. MITCHELL, T. P. (2001). Characteristics of risk and return in risk arbitrage. Journal of Finance, 56, $2135-2172$.

MANDELBROT, B. B., \& WALLIS, J. R. (1969). Some long-run properties of geophysical records. Water resources research, 5(2), 321-340.

MANDELBROT, B. B. (1971). When can price be arbitraged efficiently? A limit to the validity of the random walk and martingale models. The Review of Economics and Statistics, 225-236.

MANDELBROT, B. B. (1972). Statistical methodology for nonperiodic cycles: from the covariance to R/S analisys. Annals of Economic and Social Measurement, 1, 259-290.

MANDELBROT, B. B. (1997). Fractal and Scaling in Finance: Discontinuity, Concentration.

MANDELBROT, B. B., \& WALLIS, J. R. (1968). Noah, Joseph, and Operational Hydrology. Water Resources Research, 4, 909.

MATOS, J. A. O., GAMA, S. M. A., RUSKIN, H. J., SHARKASI, A. AL, \& CRANE, M. (2008). Time and scale Hurst exponent analysis for financial markets. Physica A: Statistical Mechanics and Its Applications, 387(15), 39103915. https://doi.org/10.1016/j.physa.2008.01.060

MATOS, O. (2006). Entropy Measures Applied to Financial Time Series - an Econophysics Approach.

MITRA, S. K. (2012). Is Hurst exponent value useful in forecasting financial time series? Asian Social Science, 8(8), 111-120. https://doi.org/10.5539/ass.v8n8p111

MONTANARI, A., TAQQU, M. S., \& TEVEROVSKY, V. (1999). Estimating long-range dependence in the presence of periodicity: an empirical study. Mathematical and computer modelling, 29(10-12), 217-228.

MOVAHED, M. S., \& HERMANIS, E. (2008). Fractal analysis of river flow fluctuations. Physica A: Statistical Mechanics and Its Applications, 387, 915-932.

NEWMAN, M. E. J. (2003). the structure and function of network. SIAM Review, 45, 167-256

PENG, C. K., BULDVREV, S. V., GOLDBERGER, A. L., HAVLIN, S., SCIORTINO, F., SIMOSNS, M., \& STANLEY, H. E. (1992). Long-Range Correlations in Nucleotide Sequences. Nature, 356, 168.

PIZZUTILO, F. (2013). A note on the effectiveness of pairs trading for individual investors.

RAMOS-REQUENA, J. P., TRINIDAD-SEGOVIA, J. E., \& SÁNCHEZ-GRANERO, M. A. (2017). Introducing Hurst exponent in pair trading. Physica $A$ : statistical mechanics and its applications, 488, 39-45.

SANCHEZ-GRANERO, M. A., SEGOVIA, J. T., \& PÉREZ, J. G. (2008). Some comments on Hurst exponent and the long memory processes on capital markets. Physica A: Statistical Mechanics and its applications, 387(22), 5543-5551.

SANCHEZ-GRANERO, M. A., FERNÁNDEZ-MARTÍNEZ, M., \& TRINIDAD-SEGOVIA, J. E. (2015). Introducing fractal dimension algorithms to calculate the Hurst exponent of financial time series. The European Physical Journal B-Condensed Matter and Complex Systems, 28, 1-17.

SANCHEZ-GRANERO, M. A., TRINIDAD-SEGOVIA, J. E., GARCÍA, J., \& FERNÁNDEZ-MARTíNEZ, M. (2015). The Effect of the Underlying Distribution in Hurst Exponent Estimation. Plos One, 28, 1-17.

SÁNCHEZ-GRANERO, M. A., TRINIDAD-SEGOVIA, J. E., \& GARCIA PEREZ, F. (2008). Some comments on Hurst exponent and the long memory processes on capital markets. Physica A: Statistical Mechanics and Its Applications, 387, 5543-5551.

TAQQU, M. S., TEVEROVSKY, V., \& WILLINGER, W. (1995). Estimators for long-range dependence: an empirlical study. Fractals, 3, 785-798.

TRINIDAD-SEGOVIA, J. E., FERNÁNDEZ-MARTÍNEZ, M., \& SANCHEZ-GRANERO, M. A. (2012). A note on goemetric method-based procedures to calculate the Hurs exponent. Physica A: Statistical Mechanics and Its Applications, 391, 2209-2214.

VEITCH, D., \& ABRY, P. (1999). A wavelet-based joint estimator of the parameters of long-range dependence. IEEE Transactions on Information Theory, 45, 878-897.

WERON, R. (2002). Estimating long-range dependence: finite sample properties and cofidence intervals. Physica 
A: Statistical Mechanics and Its Applications, 312, 285-299. 